\title{
Catalytic Activity of Nanodiamonds in Azocoupling Reaction
}

\author{
Nikita O. Ronzhin 1* , Alexey P. Puzyr'1, Andrey E. Burov², Vladimir S. Bondar1 \\ ${ }^{1}$ Institute of Biophysics SB RAS, Krasnoyarsk, Russia \\ ${ }^{2}$ Special Design-Technology Bureau “Nauka” SB RAS, Krasnoyarsk, Russia \\ Email: ${ }^{\text {roniol@mail.ru }}$
}

Received 4 June 2014; revised 3 July 2014; accepted 14 July 2014

Copyright (C) 2014 by authors and Scientific Research Publishing Inc.

This work is licensed under the Creative Commons Attribution International License (CC BY).

http://creativecommons.org/licenses/by/4.0/

cc) (i) Open Access

\begin{abstract}
The catalytic efficiency of modified nanodiamonds (MND) in reactions of interaction between organic compounds was demonstrated on the example of azocoupling reaction (hydrogen peroxide4-aminoantipyrine-phenol). It was found that catalytic action of MND was caused by redox active metal ions of Fe and $\mathrm{Cu}$ located on the MND surface. The neutralization of the ions significantly decreased catalytic properties of MND.
\end{abstract}

\section{Keywords}

Diamond Nanoparticles, Catalytic Activity, Metal Ions, Organic Reaction

\section{Introduction}

Unique surface properties of nanodiamonds synthesized by the detonation technique [1] [2], especially the abundance of different chemically active groups and high surface area, allow us to predict the prospects for application of this nanomaterial as a catalyst. Application of the nanodiamonds modified using thermal and electrochemical treatment followed by deposition of metallized palladium in catalytic oxidation reactions (gas-phase $\mathrm{CO}$ oxidation to $\mathrm{CO}_{2}$ and electrochemical hydrogen oxidation) has been reported [3] [4]. Nanodiamonds themselves have shown catalytic activity (dehydrogenation of ethylbenzene under steam-free conditions) [5].

In this work, we have experimentally demonstrated the applicability of nanodiamonds as catalysts for reaction of interaction between organic compounds on example azocoupling reaction: $\mathrm{H}_{2} \mathrm{O}_{2}$-4-aminoantipyrine-phenol. It is known that the reaction of oxidative diazotization is stimulated by the biocatalysts peroxidases [6] and accompanied by the formation of a stained reaction product (quinoneimine). Nowadays, this reaction is widely used in medical diagnostics for determination of physiologically important substances (for example, glucose,

\footnotetext{
${ }^{*}$ Corresponding author.
}

How to cite this paper: Ronzhin, N.O., Puzyr, A.P., Burov, A.E. and Bondar, V.S. (2014) Catalytic Activity of Nanodiamonds in Azocoupling Reaction. Journal of Biomaterials and Nanobiotechnology, 5, 173-178. 
cholesterol and triglycerides) as well as in ecological analysis for determination of phenol and phenolic compounds [7] [8].

In this work, we have studied MND-catalyzed azocoupling reaction $\left(\mathrm{H}_{2} \mathrm{O}_{2}\right.$-4-aminoantipyrine-phenol) at the different conditions and reagent concentrations as well as the rationale of catalytic efficiency of the MND particles in the reaction.

\section{Materials and Methods}

\subsection{Materials}

MNDs (RUDDM grade $0-125, d_{50}=49.6 \mathrm{~nm}$ and RUDDM Grade $200-500, d_{50}=270 \mathrm{~nm}$ ) exhibiting a high colloidal stability in hydrosols were produced by "Real-Dzerzhinsk” Ltd. (Russia) using a known technology [9] [10] and used in the experiments. The hydrosols with a concentration of nanoparticles up to $5 \mathrm{wt} \%$ were obtained by adding deionized water (Milli-Q system, Millipore, USA) to a portion of MND powder.

\subsection{Reagents}

The following reagents of high purity grades were used in the study: 4-aminoantipyrine (1-phenyl-2,3-dimethyl-4-aminopyrazolone) (4-AAP), phenol (Fluka, Germany), 3\% hydrogen peroxide (GalenoPharm ${ }^{\mathrm{TM}}$, Russia), EDTA (Serva, Germany), salts ( $\mathrm{NaCl}, \mathrm{MnCl}_{2}, \mathrm{FeSO}_{4}, \mathrm{CoCl}_{2}, \mathrm{NiCl}_{2}, \mathrm{CuSO}_{4}, \mathrm{MgSO}_{4}, \mathrm{CaCl}_{2}, \mathrm{CdCl}_{2}, \mathrm{ZnCl}_{2}$, $\mathrm{AlCl}_{3}$ ). Reagents solutions were prepared in situ with DI water.

\subsection{Azocoupling Reaction}

The reaction mixture contained: $0.03 \% \mathrm{H}_{2} \mathrm{O}_{2}, 0.10 \mathrm{mg} / \mathrm{ml}$ 4-AAP, $0.56 \mathrm{mg} / \mathrm{ml}$ phenol. The reaction was initiated by metal ions (in salt form) at concentration $5 \times 10^{-4} \mathrm{mg} / \mathrm{ml}$ or MND in a concentration range of $0-0.5 \mathrm{wt} \%$. After adding all reagents the samples were intensively agitated for 3 - 5 seconds on Vortex-Genie 2 g-560E (Scientific Industries, Inc., USA) and incubated at temperature $20^{\circ} \mathrm{C}$ or $40^{\circ} \mathrm{C}$.

\subsection{Measurement of the Reaction Product Yield}

To estimate the reaction product formation the spectral analysis of the stained product was carried out at a wavelength $506 \mathrm{~nm}$ (UV/VIS spectrophotometer UVIKON 943, Kontron Instruments, Italy). The samples containing MND were centrifuged at 16,000 g (Centrifuge 5415R, Eppendorf, Germany) for 10 min at $10^{\circ} \mathrm{C}$ to remove MND particles from the reaction mixture.

\subsection{Quantitative Elemental Analysis of MND Samples}

For quantitative determination of metal ions in different-sized MND clusters the elemental analysis of the nanoparticles was carried out using an electron microscope TM-1000 (Hitachi, Japan).

\section{Results and Discussion}

It was experimentally shown that the MND particles are able to catalyze the interaction between organic compounds in azocoupling reaction $\left(\mathrm{H}_{2} \mathrm{O}_{2}-4-\mathrm{AAP}\right.$-phenol). The reaction was accompanied by the formation of quinoneimine. Under chosen experimental conditions the reaction rate had a linear dependence within the range of 5 to 20 min (Figure 1). Under the same reaction conditions but without the catalyst the reaction was practically unobservable and the product was formed at neither $20^{\circ} \mathrm{C}$ nor $40^{\circ} \mathrm{C}$. The absorbance of the reaction without MND did not exceed $0.2 \%-0.3 \%$ of the absorbance of the MND-catalyzed reaction.

It has been found that the increase of reaction absorbance due to product formation was linear at phenol concentrations in the range of $0-10 \mathrm{mkg} / \mathrm{ml}$ (Figure 2). Such linear trend was observed at both $20^{\circ} \mathrm{C}$ and $40^{\circ} \mathrm{C}$ but the absorbance values at $40^{\circ} \mathrm{C}$ (Figure 2) were approximately fourfold higher than those at $20^{\circ} \mathrm{C}$.

It is evident from the dependence of optical density on the amount of catalysts (Figure 3) that the product formation at the MND concentrations up to $0.1 \mathrm{wt} \%$ has a nearly linear trend. A further increase in the concentration of nanoparticles drives the reaction to a plateau. It indicates that the reaction system is saturated with the catalysts under the experimental conditions used. 


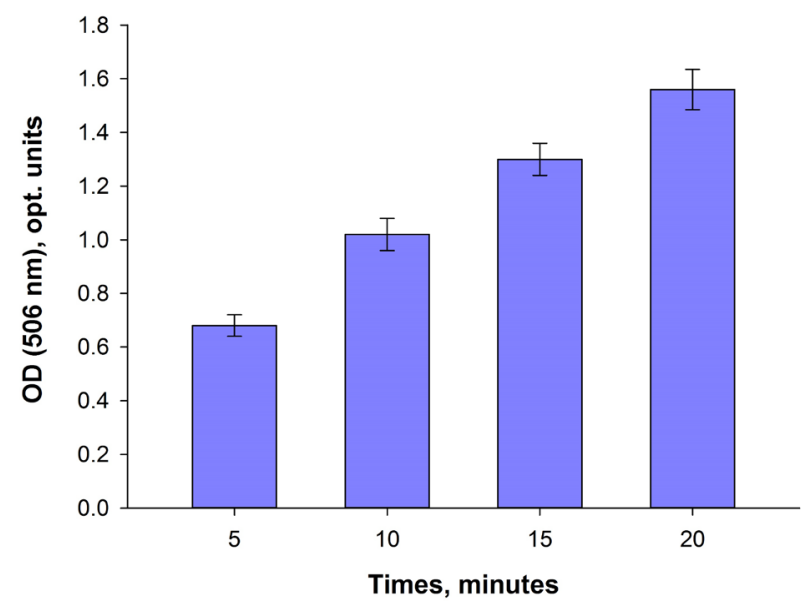

Figure 1. The time dependence of product yield in the azocoupling reaction catalyzed by MND (nanoparticles concentration was $0.5 \mathrm{wt} \%$ ) at $20^{\circ} \mathrm{C}$.

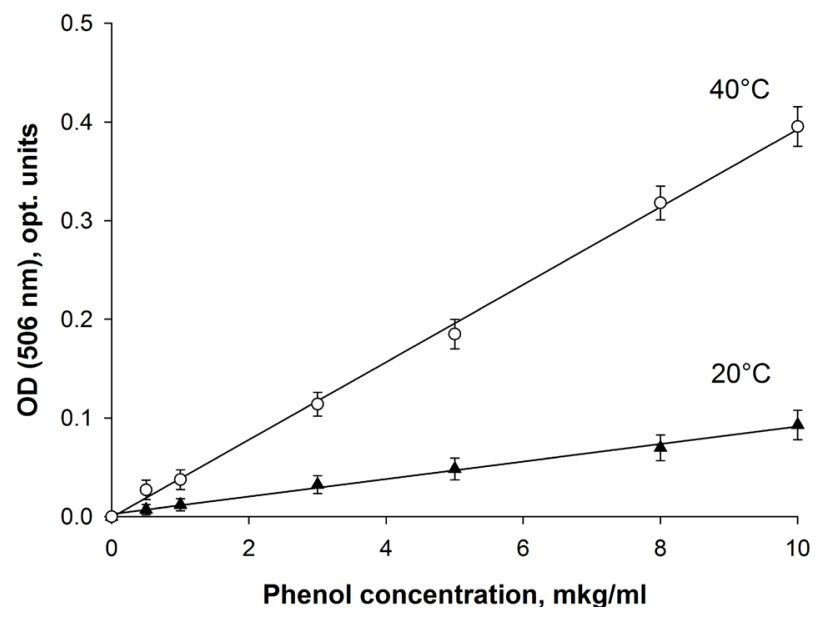

Figure 2. The product yield in the MND-catalyzed reaction vs. phenol concentration (10 min incubation at $20^{\circ} \mathrm{C}$ and $40^{\circ} \mathrm{C}$ ).

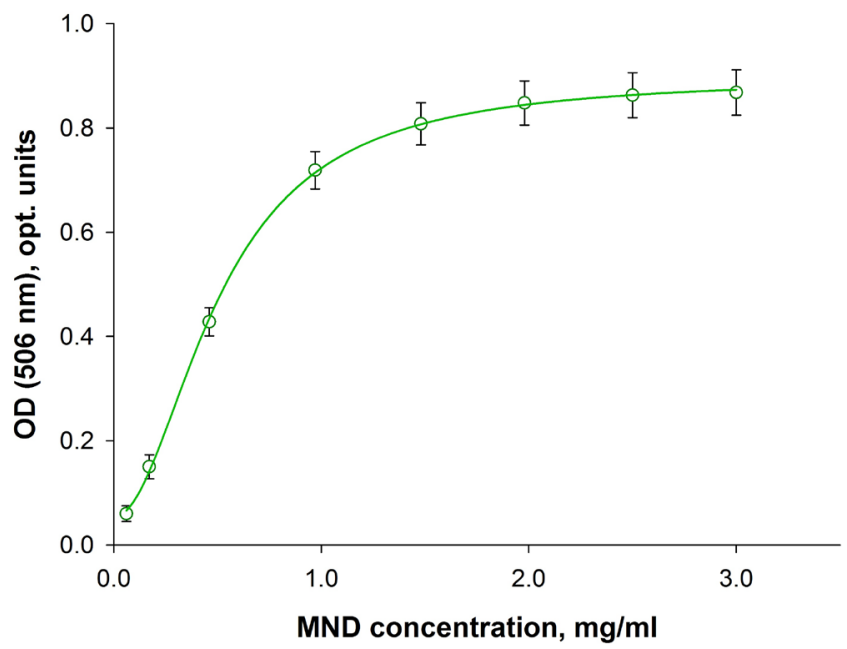

Figure 3. The product yield in the MND-catalyzed reaction vs. concentration of the nanoparticles $\left(10 \mathrm{~min}\right.$ incubation at $\left.40^{\circ} \mathrm{C}\right)$. 
The dependence of optical density on $\mathrm{H}_{2} \mathrm{O}_{2}$ concentration has a hyperbolic shape (Figure 4). In this process, the addition of hydrogen peroxide to the reaction system in the concentration range of $0 \%-0.003 \%$ is accompanied by a virtually linear increase in the yield of reaction product.

We had supposed that the MND-catalyzed azocoupling reaction was initiated by metal ions found on the MND surface [9] [11]. In order to understand a principle of MND catalytic action in the reaction, it was investigated which metal ions are able to catalyze the reaction $\mathrm{H}_{2} \mathrm{O}_{2}-4$-AAP-phenol. For this purpose the metal salt containing the metal ions found on the MND surface were examined: monovalent $\mathrm{Na}$ ions; bivalent ions of first transition series $\mathrm{Mn}, \mathrm{Fe}, \mathrm{Co}, \mathrm{Ni}, \mathrm{Cu}$; bivalent $\mathrm{Mg}, \mathrm{Ca}, \mathrm{Cd}, \mathrm{Zn}$ ions and trivalent $\mathrm{Al}$ ions.

It was experimentally shown (Figure 5) that among the first transition series only $\mathrm{Fe}$ and $\mathrm{Cu}$ ions were able to catalyze the azocoupling reaction in aqueous media. The other ions of the first transition series $\mathrm{Mn}$, Co and $\mathrm{Ni}$ ions) did not catalyze the reaction - the reaction dynamics with these ions was practically the same as the control reaction dynamics (reaction without catalyst) (Figure 5).

As is shown in Figure 5, kinetics of the reactions catalyzed by Fe ions and $\mathrm{Cu}$ ions are different. Within the range of $0-50 \mathrm{~min}$, the reaction with $\mathrm{Fe}$ ions carried more intensive than the reaction with $\mathrm{Cu}$ ions. In the range of $50-100 \mathrm{~min}$, formation of the product was more intensive in the presence of $\mathrm{Cu}$ ions, after then the reaction stopped and the product yield did not increase. At the same time, the Fe-catalyzed reaction did not stop-product formation grew practically linearly in the range of 50 - $140 \mathrm{~min}$.

Under the chosen experimental conditions (aqueous media, concentrations of reagents and catalysts) monovalent $\mathrm{Na}$ ions; bivalent $\mathrm{Mg}, \mathrm{Ca}, \mathrm{Cd}, \mathrm{Zn}$ ions and trivalent $\mathrm{Al}$ ions did not catalyze the azocoupling reaction. The reaction dynamics with these ions was practically the same as the control reaction dynamics.

The addition of EDTA (chelant of bivalent metal ions) in the reaction almost completely neutralized catalytic properties of $\mathrm{Fe}$ and $\mathrm{Cu}$ ions. The product yield of the reaction catalyzed $\mathrm{Fe}$ and $\mathrm{Cu}$ ions in the presence of EDTA (at equimolar ion-chelant ratio) was $15 \%$ and $2 \%$ respectively of the EDTA-absent reaction. This result is in agreement with known binding constants of $\mathrm{Fe}$ and $\mathrm{Cu}$ ions with EDTA [12].

In the MND-catalyzed reactions, it was shown (Figure 6) that product formation was twofold higher in the present of small-sized MND clusters $\left(\mathrm{d}_{50}=49.6 \mathrm{~nm}\right)$ in comparison with the product formation observed in the reaction catalyzed by large-sized MND clusters $\left(d_{50}=270 \mathrm{~nm}\right)$. Bearing in mind the obtained data: 1$)$ only Fe and $\mathrm{Cu}$ ions were able to catalyze the azocoupling reaction and 2) both ions were found on MND surface [9] [11], the quantitative elemental analysis of these nanodiamond samples was carried out.

This analysis showed (Table 1) that contents of $\mathrm{Fe}$ and $\mathrm{Cu}$ ions in small-sized MND clusters were significantly higher (2 and 1.5 fold respectively) than their contents in large-sized MND clusters. Thus, it is arguable that the differences of catalytic activity of different-sized MND clusters in the azocoupling reaction are associated with different amount of $\mathrm{Fe}$ and $\mathrm{Cu}$ ions on the surface of nanodiamonds.

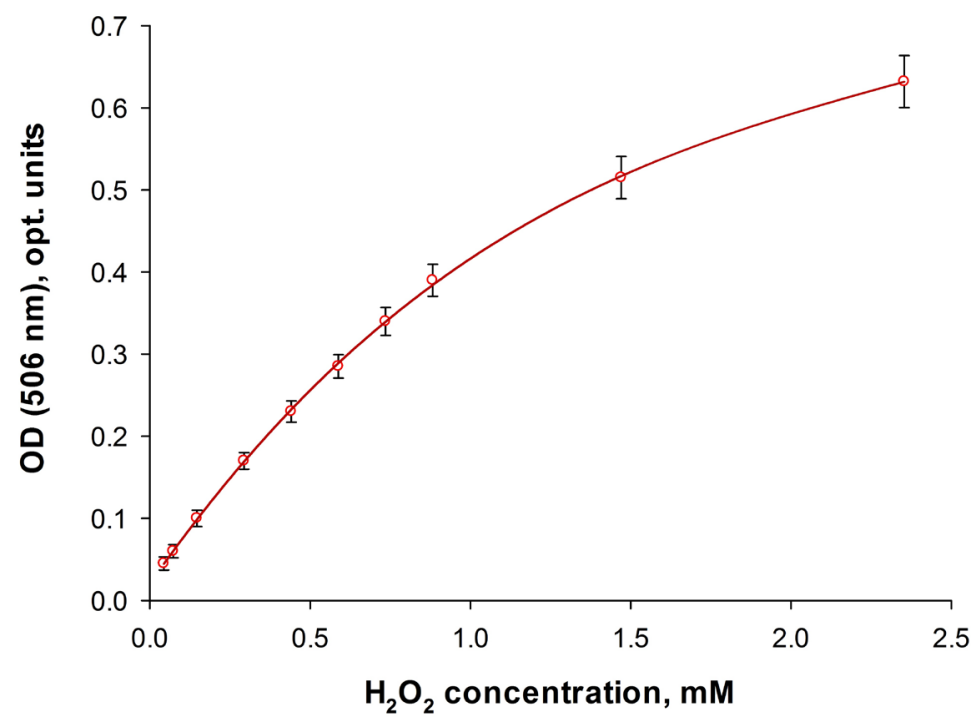

Figure 4. The product yield in the MND-catalyzed reaction vs. hydrogen peroxide concentration $\left(10 \mathrm{~min}\right.$ incubation at $\left.40^{\circ} \mathrm{C}\right)$. 


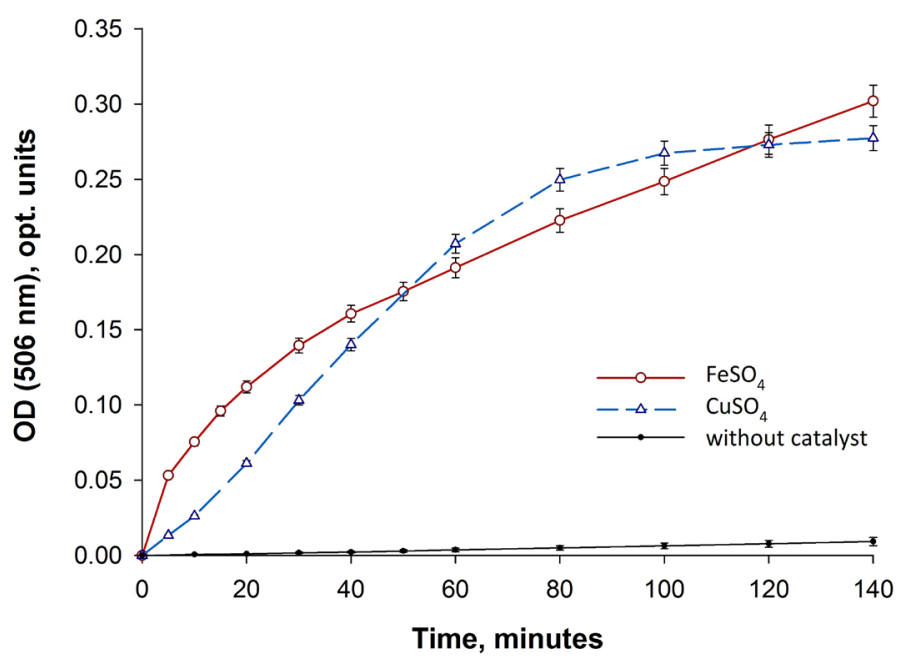

Figure 5. The time dependence of product formation in $\mathrm{H}_{2} \mathrm{O}_{2}-4$-AAPphenol reaction catalyzed by different metal ions and without catalyst.

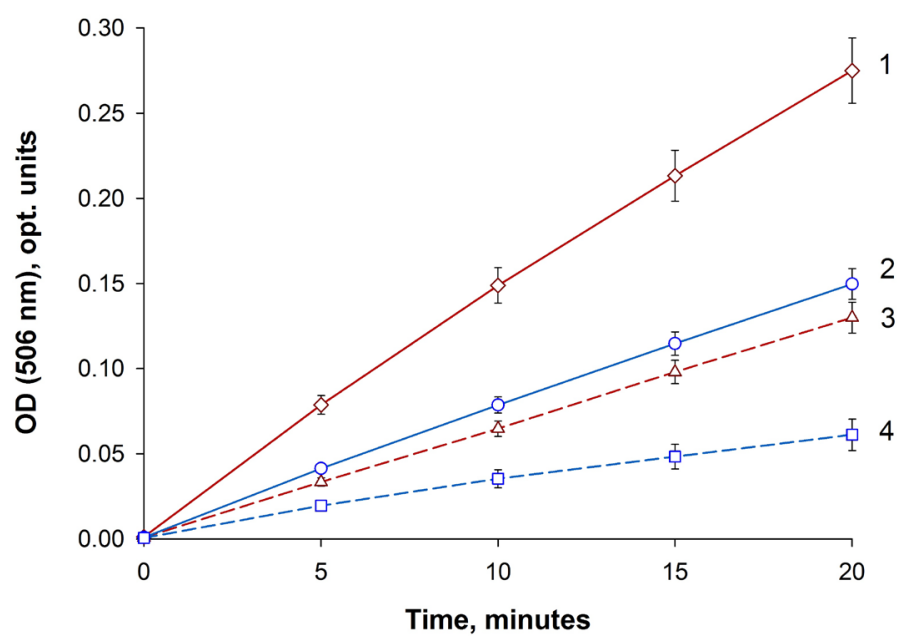

Figure 6. The time dependence of product formation in $\mathrm{H}_{2} \mathrm{O}_{2}-4$-AAPphenol reaction catalyzed by small-sized MND clusters $\left(d_{50}=49.6 \mathrm{~nm}\right)$ and large-sized MND clusters $\left(\mathrm{d}_{50}=270 \mathrm{~nm}\right)$ : original MNDs $(1,2)$ and EDTA-treated MNDs $(3,4)$.

Table 1. Contents of iron and cupper impurities on the surface of different-sized MND clusters.

\begin{tabular}{ccc}
\hline \multirow{2}{*}{ Element impurities } & \multicolumn{2}{c}{ Samples of MND } \\
\cline { 2 - 3 } & RUDDM $0-125\left(\mathrm{~d}_{50}=49.6 \mathrm{~nm}\right)$ & RUDDM $200-500\left(\mathrm{~d}_{50}=270 \mathrm{~nm}\right)$ \\
\hline $\mathrm{Fe}, \mathrm{mkg} / \mathrm{mg}$ & $4.6 \pm 0.3$ & $3.1 \pm 0.3$ \\
$\mathrm{Cu}, \mathrm{mkg} / \mathrm{mg}$ & $1.3 \pm 0.2$ & $0.6 \pm 0.2$ \\
\hline
\end{tabular}

Additionally, it was shown that pretreatment of the MND particles with EDTA resulted in significant reduction of their catalytic properties. In the reaction with small-sized and large-sized MND clusters pretreated by EDTA, the product formation was decreased by 2 and 2.5 times, respectively (Figure 6). It is an additional indication on the role of $\mathrm{Fe}$ and $\mathrm{Cu}$ surface ions in mechanism of MND catalytic action in the azocoupling reaction. At the same time, this result allows making an important suggestion. As EDTA pretreatment of the MND did not lead to the total loss of their catalytic properties, it should not be ruled out additional catalytic action, for example, with the participation of chemically active oxygen-containing functional groups existing on MND sur- 
face [11].

\section{Conclusions}

1) In the work, we have demonstrated the catalytic efficiency of the MND particles in reactions of interaction between organic compounds on the example of the azocoupling reaction $\left(\mathrm{H}_{2} \mathrm{O}_{2}\right.$-4-AAP-phenol). It was found that catalytic action of MND was due to Fe and $\mathrm{Cu}$ ions located on the MND surface. These results increase our knowledge about MND catalytic function in the reactions and can be used for designing new MND-based indicating systems for application, for example, in ecological monitoring.

2) The catalytic efficiency of different-sized MND clusters in the azocoupling reaction depends on the amount of surface Fe and $\mathrm{Cu}$ ions, which neutralization leads to significant reduction of MND catalytic properties.

3) We do not exclude that the catalytic mechanism of the MND-catalyzed reaction can include, along with Fe and $\mathrm{Cu}$ ions, other chemically active oxygen-containing groups located on the MND surface [11].

\section{Acknowledgements}

The study was supported by the Presidium of RAS (Program No. 24, Project No. 57). The authors are grateful to Mr. Kargin (ICCT SB RAS, Krasnoyarsk) for elemental analysis of MND samples.

\section{References}

[1] Chiganova, G.A. (1994) Study of Surface Properties of Ultrafine Diamonds. Colloid Journal, 56, 266-268.

[2] Mochalin, V.N., Shenderova, O., Ho, D. and Gogotsi, Y. (2012) The Properties and Applications of Nanodiamonds. Nature Nanotechnology, 7, 11-23. http://dx.doi.org/10.1038/nnano.2011.209

[3] Bogatyreva, G.P., Ishchenko, E.V. and Marinich, M.A. (2000) Catalytic Properties of Pd, Pd-Ag, and Ag Deposited onto Diamond Submicron Powders. Sverkhtverdye Materialy, 2, 72-77.

[4] Bogatyreva, G.P., Marinich, M.A., Ishchenko, E.V., Gvyazdovskaya, V.L., Bazalii, G.A. and Oleinik, N.A. (2004) Application of Modified Nanodiamonds as Catalysts of Heterogeneous and Electrochemical Catalyses. Physics of the Solid State, 46, 718-721. http://dx.doi.org/10.1134/1.1711462

[5] Zhang, J., Sheng Su, D., Blume, R., Schlogl, R., Wang, R., Yang, X. and Gajovic, A. (2010) Surface Chemistry and Catalytic Reactivity of a Nanodiamond in the Steam-Free Dehydrogenation of Ethylbenzene. Angewandte Chemie International Edition, 49, 8640-8644. http://dx.doi.org/10.1002/anie.201002869

[6] Yeremin, A.N., Semashko, T.V. and Mikhailova, R.V. (2006) Co-Oxidation of Phenol and 4-Aminoantipyrine, Catalyzed by Polymers and Co-Polymers of Horse Radish Root and Glucose Oxidase of Penicillium funiculosum 46.1. Applied Microbiology and Biotechnology, 42, 452-461.

[7] Keppy, N.K., Bain, G. and Allen, M.W. (2009) Enzymatic Colorimetric Methods for the Analysis of Human Serum by UV-Visible Spectroscopy. Thermo Fisher Scientific, Madison.

[8] Kumar, A., Mishra, R.K. and Roy, S.S. (2004) Studies on Impact of Industrial Pollution on Biochemical and Histological Changes in a Catfish, Mystus vittatus (Bloch). In: Kumar, A., Ed., Industrial Pollution \& Management, APH Publishing, New Delhi, 1-43.

[9] Bondar, V.S. and Puzyr, A.P. (2004) Nanodiamonds for Biological Investigations. Physics of the Solid State, 46, 716719. http://dx.doi.org/10.1134/1.1711457

[10] Puzyr, A.P. and Bondar, V.S. (2003) Method of Production of Nanodiamonds of Explosive Synthesis with an Increased Colloidal Stability. RU Patent No. 2252192.

[11] Gibson, N., Shenderova, O., Luo, T.J.M., Moseenkov, S., Bondar, V., Puzyr, A., Purtov, K., Fitzgerald, Z. and Brenner, D.W. (2009) Colloidal Stability of Modified Nanodiamond Particles. Diamond and Related Materials, 18, 620-626. http://dx.doi.org/10.1016/j.diamond.2008.10.049

[12] Metzler, D.E. (2003) Biochemistry. The Chemical Reactions of Living Cells. 2nd Edition, Academic Press, Waltham. 
Scientific Research Publishing (SCIRP) is one of the largest Open Access journal publishers. It is currently publishing more than 200 open access, online, peer-reviewed journals covering a wide range of academic disciplines. SCIRP serves the worldwide academic communities and contributes to the progress and application of science with its publication.

Other selected journals from SCIRP are listed as below. Submit your manuscript to us via either submit@scirp.org or Online Submission Portal.
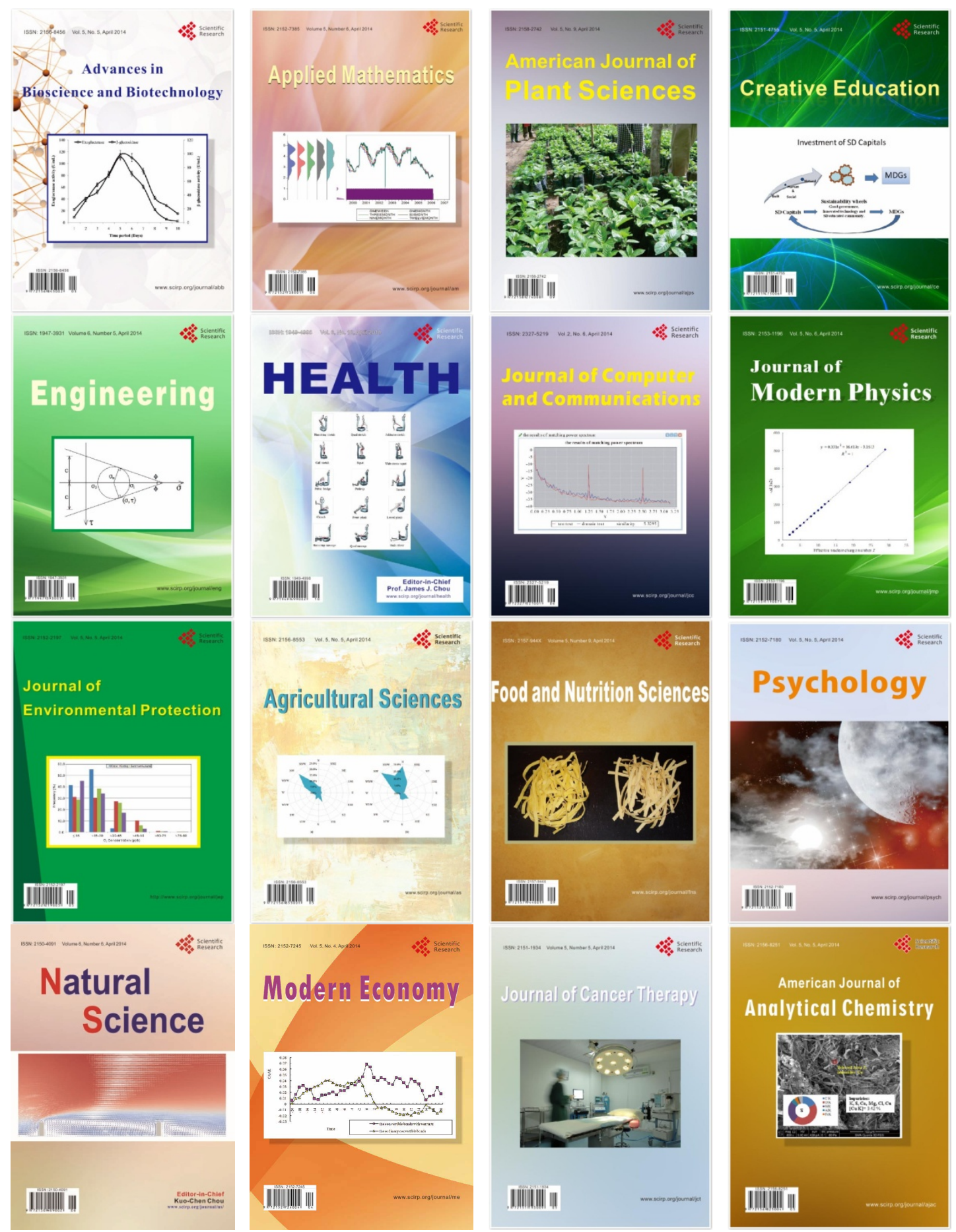